\title{
A CONTABILIDADE GERENCIAL E A LEI DE RESPONSABILIDADE FISCAL
}

Juliana Luisa Marcuzzo ${ }^{1}$

Prof. Ms. Luiz Antonio Rossi de Freitas ${ }^{2}$

\section{Resumo}

Desde a criação do estado um dos maiores problemas enfrentados na administração pública é o endividamento. A Lei de Responsabilidade Fiscal traz uma mudança institucional e cultural no trato com o dinheiro púbico, estabelecendo normas orientadoras das finanças públicas no país e rígidas punições aos administradores que não manterem o equilíbrio de suas contas. O presente trabalho visa apresentar um modelo de relatório gerencial para pequenos Municípios que expressa a situação financeira a curto prazo, servindo como um instrumento à disposição do administrador público para a tomada de decisões.

\section{Palavras Chaves:}

Finanças - Responsabilidade Fiscal - Contabilidade

\section{ABSTRACT}

The debt is one of the largest problems faced by the public administration since the criation of the state. The Law of Fiscal Responsibility brings an institutional and cultural change in dealing with public money, establishing guiding norms to national public finances and severe penalties to administrators who do not maintain the balance of their accounts. This paper presents a model of managerial report for small districts, which expresses a short term financial situation, serving as an useful instrument whenever the public administrator has to take a decision.

\section{Key Words:}

Finances - Fiscal Responsibility - Accountancy

\footnotetext{
${ }^{1}$ Especialista em Controladoria e Finanças-UFSM/RS. E-mail: jlm.cont@terra.com.br ${ }^{2}$ Mestre em Engenharia da Produção-UFSM/RS, Professor do Departamento de Ciências Econômicas e Ciências Contábeis da UFSM/RS.
} 


\section{Introdução}

A preocupação com o equilíbrio das finanças públicas existe desde a criação do estado e foi tornando-se cada vez maior em virtude do crescimento das funções da administração pública.

A Lei 4.320/64 que instituiu normas gerais de direito financeiro para elaboração e controle dos orçamentos e balanços da União, dos Estados, dos Municípios e do Distrito Federal, preocupou-se com o equilíbrio das finanças públicas reforçando a obrigatoriedade, já expressa na Constituição Federal, da elaboração de instrumentos de planejamento representados pelo plano plurianual, diretrizes orçamentárias e orçamento anual, sendo este último, o principal mecanismo para o controle das finanças públicas.

Entretanto, o administrador público, principalmente a nível municipal, atribuiu ao orçamento um outro sentido, ou seja, a elaboração do orçamento passou a ser realizada simplesmente para atender um dispositivo legal e não para representar uma ferramenta de ligação entre planejamento e finanças, permitindo a realização de gastos maiores do que os valores arrecadados e, por conseqüência, o aumento do endividamento.

A Lei de Responsabilidade Fiscal aprovada em 04 de maio de 2000, veio suprir uma lacuna da Lei 4.320/64 pois além de estabelecer normas orientadoras das finanças públicas, instituiu, também, severas punições para aqueles governantes que não souberem administrar os recursos públicos durante o seu mandato, deixando dívidas para seus sucessores e assumindo compromissos que sabem, de antemão, não poder honrar.

Com a aprovação da Lei de Responsabilidade Fiscal as informações a respeito da situação financeira tornam-se de fundamental importância, constituindose objetivo deste trabalho, através da utilização de dados da contabilidade e do orçamento, elaborar um relatório gerencial que possibilite ao administrador, em qualquer época do ano, ter conhecimento da situação financeira no final do exercício, e por conseqüência, tomar decisões administrativas quanto à consecução de gastos. 


\section{Instrumentos de controle das finanças públicas}

Com a finalidade de manter o controle das finanças públicas a Constituição Federal instituiu em seu artigo 165 três leis visando dotar o setor público de um processo de planejamento a curto, médio e longo prazo, sendo estas:

a) lei do plano plurianual: é o plano de governo no que tange a investimentos públicos e programas de duração continuada, estabelecendo as diretrizes e metas da administração durante o seu mandato;

b) lei das diretrizes orçamentárias: representam a parte do plano plurianual que pretende-se realizar para o próximo ano, servindo assim, para orientar a elaboração do orçamento e sua execução, dispondo, ainda, sobre as alterações na legislação tributária; e

c) lei do orçamento anual: parte dos objetivos traçados nas diretrizes orçamentárias fixando valores para as despesas projetadas e, de igual forma para as receitas.

Para SERRA (1997) "imprime-se com isso, maior racionalidade no processo orçamentário, na medida em que estas três leis não constituem peças estanques, mas são dispostas de maneira hierárquica e vinculada de forma a orientar o planejamento da atividade administrativa, repercutindo, diretamente, na situação financeira".

Porém, até a institucionalização da Lei de Responsabilidade Fiscal estes instrumentos eram elaborados para atender a uma exigência legal. As diretrizes, na maioria das vezes, continham matérias estranhas ao plano plurianual ou simplesmente representavam uma cópia deste, o orçamento não contemplava todos os objetivos das diretrizes em termos financeiros e, muitas vezes, o valor orçado para a realização dos programas de trabalho era menor do que o seu real custo.

Os governantes realizavam os programas de trabalho sem observar 0 processo de planejamento, provocando desequilíbrio na execução orçamentária que refletia-se nos crescentes déficits públicos.

\section{O orçamento e seu papel no controle financeiro}

Para SILVA, "o orçamento é um plano de trabalho governamental expresso em termos monetários, que evidencia a política econômico-financeira do Governo e em cuja elaboração foram observados os princípios da unidade, universalidade, anualidade, especificação e outros". (1996, p.37) 
MACHADO JR. e REIS, em comentários à Lei 4.320/64, dizem que o orçamento desempenha sua função no momento em que se alia ao planejamento, com isso tornando-se possível a operacionalização dos planos, porque os monetariza, isto é, coloca-os em função dos recursos financeiros disponíveis, permitindo que o planejador tenha os pés no chão, em face das disponibilidades dos recursos financeiros. Os autores definem que " o orçamento, portanto, é uma técnica cujo maior significado moderno consiste, precisamente, em ligar os sistemas de planejamento e finanças pela expressão quantitativa financeira e física dos programas de trabalho do governo, valendo este conceito também para o orçamento empresarial". (2000/2001, p. 12)

Para finalmente atingir seu papel de controlador das finanças é de fundamental importância que o orçamento expresse a realidade, da forma mais precisa possível, quanto à previsão das receitas e à fixação das despesas. Além disso, deve haver o constante acompanhamento da execução orçamentária pois o resultado orçamentário representa o principal indicador da situação financeira a curto prazo.

Pode-se ter três situações distintas no orçamento quanto ao resultado financeiro, tendo em vista que segundo a Lei 4.320/64 em seu artigo 35 adota-se o regime de caixa para as receitas e de competência para as despesas:

a) superávit: quando as receitas arrecadadas excedem as despesas empenhadas ${ }^{3}$

b) déficit:quando as receitas arrecadadas são menores que as despesas empenhadas; e

c) equilíbrio: quando o montante das receitas arrecadadas é igual o montante das despesas empenhadas.

\subsection{Receitas públicas}

De acordo com a Lei 4.320/64 em seu artigo $9^{\circ}$ a receita se classifica em sentido lato ou restrito, tal classificação fica claramente evidenciada segundo SILVA que assim diz: "ingressos ou receitas correspondem a todas as quantias recebidas pelos cofres públicos, ao passo que receitas públicas correspondem aos

\footnotetext{
${ }^{3}$ Empenho, de acordo com o artigo 58 da Lei 4.320/64 "é o ato emanado de autoridade competente que cria para o Estado obrigação de pagamento pendente ou não de condição”. Representa o momento em que faz-se a reserva da dotação orçamentária.
} 
ingressos que, integrando-se ao patrimônio público sem quaisquer reservas, condições ou correspondências no passivo, vem acrescentar o seu vulto como um elemento novo e positivo". (1996, p. 86)

KOHAMA (1998), diz que a receita pública pode ser dividida em dois grupos:

a) receitas orçamentárias: estão consubstanciadas no orçamento público, consignadas na Lei Orçamentária, cuja especificação deverá obedecer a discriminação constante do Anexo no. 3, da Lei Federal n. 4.320/64; e

b) receitas extra-orçamentárias: compreendem os recolhimentos feitos que constituirão compromissos exigíveis, cujo pagamento independe de autorização orçamentária e, portanto, independe de autorização legislativa.

SILVA (1996) reforça o conceito, dizendo que as receitas extra-orçamentárias compreendem entradas em dinheiro ou créditos de terceiros, de que o estado é devedor como um simples depositário.

\subsection{Despesas públicas}

Segundo SILVA , “...desembolsos ou despesas correspondem a todas as quantias despendidas pela Fazenda Pública, ao passo que as despesas públicas correspondem ao desembolso que, dentro de uma autorização legislativa para a execução do trabalho do Governo, vem a diminuir o patrimônio como um elemento novo e negativo". (1996, p. 101)

As despesas, de acordo com KOHAMA (1998), classificam-se em:

a) despesas orçamentárias: a realização depende de autorização legislativa não podendo se realizar sem crédito orçamentário correspondente; em outras palavras, é a que integra o orçamento; e

b) despesas extra-orçamentárias: são pagas à margem da lei orçamentária e, portanto, independente de autorização legislativa, pois se constituem em saídas do passivo financeiro, compensatórias de entradas no ativo financeiro, oriundas de receitas extra-orçamentárias, correspondendo à restituição ou entrega de valores recebidos, como cauções, depósitos, consignações e outros.

Dos conceitos evidencia-se que as receitas e despesas orçamentárias são as reais responsáveis pela formação do resultado financeiro, haja visto, que as receitas e despesas extra-orçamentárias são compensatórias e, somente, quando houverem 
entradas extra-orçamentárias maiores do que as saídas extra-orçamentárias e viceversa tais valores influenciarão efetivamente o resultado.

\section{Dívida pública}

A dívida pública decorre dos déficits orçamentários, das despesas extraorçamentárias e das contratações de obrigações a longo prazo constantes no passivo permanente, sendo que, segundo a Lei Federal 4.320/64 em seus artigos 92 e 98 a dívida pública divide-se em fundada e flutuante.

\subsection{Dívida fundada}

Compreende os compromissos de exigibilidade superior a 12 meses, contraídos para atender a desequilíbrio orçamentário ou a financiamentos de obras ou serviços públicos. A dívida fundada consta no passivo permanente e passa a fazer parte do passivo financeiro à medida que vai sendo empenhada e liquidada, momento em que é baixada do passivo permanente.

Poderá ser contraída mediante contratos ou emissão de títulos da dívida pública desdobrando-se em consolidada quando decorrente do apelo ao crédito público representado por apólices, obrigações e cédulas e não consolidada proveniente de operações de crédito em que os títulos de dívida são os próprios instrumentos do contrato.

\subsection{Dívida flutuante}

Compreende os compromissos de curto prazo, constantes no passivo financeiro, sendo, portanto, o resultado de operações de caráter financeiro que se refletem no fluxo de caixa e no patrimônio financeiro, decorrente ou não da execução do orçamento.

Tendo em vista que o controle da dívida flutuante é o principal objetivo do relatório a ser desenvolvido neste estudo, é de fundamental importância a conceituação de cada um dos elementos que a compõe, os quais estão assim enumerados no artigo 92 da Lei Federal 4.320/64:

a) restos a pagar excluídos os serviços da dívida: são as despesas empenhadas, mas não pagas até o dia 31 de dezembro, distinguindo-se as processadas das não processadas, ou seja, são resíduos passivos oriundos da despesa orçamentária empenhada mas não paga; 
b) serviços da dívida a pagar: compreendem as parcelas de amortização e de juros da dívida fundada ou de dívida consolidada, podendo-se afirmar que é uma dívida flutuante por conversão da dívida fundada;

c) depósitos: compreendem as cauções ou garantias recebidas de terceiros para execução de contratos de obras e fornecimento em dinheiro, bem como as arrecadações por conta de terceiros, ou seja, as consignações; e

d) débitos de tesouraria: referem-se às dívidas provenientes de operações de crédito a curto prazo para antecipação da receita orçamentária, sendo realizadas para atender a insuficiências de caixa ou tesouraria.

Durante o exercício, as contas a pagar representam dívida flutuante, pois são os restos a pagar ainda não inscritos.

\section{A lei de responsabilidade fiscal e sua influência no controle das finanças públicas}

Vivendo em uma era da administração pública marcada por governantes que administram as contas públicas gastando mais do que arrecadam a Lei complementar 101 de 04 de maio de 2000 (Lei de Responsabilidade Fiscal), vem cumprir importante lacuna para a obtenção do equilíbrio fiscal do País, ao estabelecer regras claras para a adequação de despesas públicas em níveis compatíveis com as receitas de cada ente da federação, envolvendo todos os poderes.

Segundo KHAIR (2000), a Lei de Responsabilidade Fiscal apóia-se em quatro eixos para cumprir sua função de reguladora das finanças públicas: planejamento, transparência, controle e responsabilização.

O planejamento é aprimorado pela criação de novas informações, metas, limites e condições para a renúncia da receita e para a geração de despesas, inclusive com pessoal e de seguridade, para assunção de dívidas, para realização de operações de crédito e para concessão de garantias.

A transparência é concretizada com a divulgação ampla, de quatro relatórios de acompanhamento da gestão fiscal, que permitem identificar receitas e despesas: anexo de metas fiscais, anexo de riscos fiscais, relatório resumido da execução orçamentária e relatório de gestão fiscal. 
O controle caracteriza-se pela maior transparência e pela qualidade das informações, exigindo uma ação fiscalizadora mais efetiva e contínua dos tribunais de contas e a criação de sistemas de controle interno nos órgãos.

A responsabilização deverá ocorrer sempre que houver o descumprimento das regras, com a suspensão das transferências voluntárias ${ }^{4}$, das garantias e da permissão para contratação de operações de crédito, inclusive ARO (adiantamento da receita orçamentária). Os responsáveis sofrerão as sanções previstas na legislação que trata dos crimes de responsabilidade fiscal (Lei Federal 10.028/2000).

Inúmeras foram as divulgações nos meios de comunicação, marcadas por explicações a respeito da nova lei, medidas tomadas pelos governantes para adequação as suas regras, bem como protestos quanto à rigidez do seu conteúdo, evidenciando-se manchetes tais como:

"Lei assusta prefeitos empossados - rigoroso código de conduta deve impedir o endividamento e reduzir atos de sonegação e corrupção". (Iglesias, 2001, p. 2)

"Novos prefeitos, velhos problemas - a primeira semana dos novos prefeitos foi marcada por reclamações em relação à herança recebida... dívidas deixadas pelo antecessor...". (Araújo, 2001, p. 6)

"Competência desafiada - o objetivo da Lei de Responsabilidade Fiscal é justamente o de estimular a formação de uma nova cultura administrativa no país". (Zero Hora, 2001, p. 16)

"Prefeito adota tática do chorinho - o empréstimo de máquinas, equipamentos e serviços por amigos ajudam o prefeito e o vice de Quatro Irmãos a economizar". (Zero Hora, 2001, p. 8).

"Prefeitos limitam gastos com pessoal". ( Araújo, 2001, p. 6)

Desde a aprovação da lei, porém, o governo foi inflexível, e a medida, agora, é adaptar-se a era da responsabilidade fiscal.

A Lei de Responsabilidade Fiscal em seu artigo 42 expressa uma de suas mais importantes restrições, criando limitações de empenho no último ano de mandato, ou seja, nos últimos oito meses de mandato os governantes não poderão contrair obrigações de despesas que não possam ser cumpridas integralmente

\footnotetext{
4 “Transferência voluntária é a entrega de recursos correntes ou de capital de outro ente da federação, a título de cooperação, auxílio ou assistência financeira, que não decorra de determinação constitucional, legal ou os destinados ao Sistema Único de Saúde”. ( KHAIR, 2000, p. 36)
} 
nesse período ou que tenham parcelas a serem pagas no exercício seguinte sem que haja suficiente disponibilidade de caixa para esse efeito.

Este dispositivo visa atacar uma ocorrência comum que é o significativo aumento da despesa pública no último ano de mandato.

Por outro lado, a lei também preocupou-se em regular os gastos nos demais períodos exigindo em seu artigo $8^{\circ}$ que até 30 dias após a publicação dos orçamentos, o poder executivo deverá estabelecer a programação financeira e o cronograma mensal de desembolso, sendo este último, um instrumento de controle de tesouraria ou de caixa, em que se prevêem as receitas e os pagamentos das obrigações, que vão sendo assumidas à medida que o orçamento vai sendo executado.

A programação das contas pelos instrumentos antes citados visa, principalmente, manter o equilíbrio entre a receita arrecadada e a despesa realizada no decorrer do exercício, pois de nada adianta o governo não aumentar suas contas no último ano de mandato se já encontra-se com uma situação deficitária em decorrência de períodos anteriores.

A não observância nas regras de controle das despesas públicas poderá acarretar aos governantes penas de detenção ou reclusão que variam de 6 meses a 4 anos. Com relação às punições KHAIR afirma: "Para que a Lei torne-se efetiva, é preciso garantir a responsabilização efetiva e ágil de seus transgressores, sob pena de cair em descrédito". (2000, p. 70)

\section{A lei de responsabilidade fiscal e sua implantação a nível municipal}

Desde a aprovação da Lei de Responsabilidade Fiscal a maior preocupação foi com a sua aplicação a nível municipal, o que ficou expresso em seu artigo 64: "a União prestará assistência técnica e cooperação financeira aos Municípios para a modernização das respectivas administrações tributária, financeira, patrimonial e previdenciária, com vistas ao cumprimento das normas desta Lei Complementar". (Lei Complementar 101 de 04.05.2000)

Pelo senso de 1996, existem 5.507 Municípios, dos quais 5.027 (91,3\%) com uma população de menos de 50.000 habitantes, recebendo estes um tratamento mais favorecido nas regras da lei de responsabilidade fiscal. Logo, a preocupação justifica-se pelo fato do elevado número de prefeituras de pequeno porte e de 
interior, as quais não possuem infra estrutura tecnológica faltando um sistema eficaz para administração de suas finanças, bem como, deficiência de pessoal qualificado.

\section{A contabilidade gerencial e seu papel na administração das contas públicas}

As exigências da Lei de Responsabilidade Fiscal aliadas às punições a serem aplicadas aos administradores que não cumprirem suas regras, fazem com que estes exijam cada vez mais informações de suas finanças, informações estas, que, muitas vezes, não são geradas pela contabilidade tradicional, cabendo a utilização da contabilidade gerencial para a criação de instrumentos eficientes de controle.

Para IUDICIBUS,

A contabilidade gerencial pode ser caracterizada, superficialmente, como um enfoque especial conferido a várias técnicas e procedimentos contábeis já conhecidos e tratados na contabilidade financeira, na contabilidade de custos, na análise financeira e de balanços etc., colocados numa perspectiva diferente, num grau de detalhe mais analítico ou numa forma de apresentação e classificação diferenciada, de maneira a auxiliar os gerentes das entidades em seu processo decisório. (1991, p.15)

Observa-se que a contabilidade gerencial é, em realidade uma contabilidade mais administrativa, tendo em vista que as informações por ela geradas têm efeitos mais internos que externos e porque não está sujeita a formalidades como os demais subsistemas contábeis.

\section{Um relatório gerencial para o controle a curto prazo das finanças municipais}

O relatório aqui evidenciado foi elaborado no Município de Restinga Seca (RS), com aproximadamente 16.000 habitantes.

Tendo em vista a Lei de responsabilidade fiscal, a atenção do prefeito em exercício voltou-se para o cumprimento do dispositivo legal. Consciente das punições solicitou ao setor financeiro uma previsão da situação financeira do município no encerramento do exercício, bem como da participação de cada secretaria neste resultado.

Visando atender às necessidades de informações exigidas, desenvolveu-se um relatório baseado nos dados produzidos pelos sistema de contabilidade e orçamento do Município, bem como em um reestudo da provável arrecadação para os períodos subseqüentes, apresentando-se resumidamente conforme quadro 1. 
QUADRO 1 - Modelo de Relatório Gerencial

RELATÓRIO DA SITUAÇÃO FINANCEIRA A CURTO PRAZO - POSIÇÃO PARA 31/12I

A Participação das secretarias no resultado financeiro

A.1 Saldo de recursos financeiros exercício anterior (SA-Saldo Anterior)

188.748

A.2 Receita orçamentária arrecadada até a data do relatório (RA-Receita do Ano)

3.497 .934

A.3 Receita orçamentária a arrecadar até 31/12/

A.4 Saldo extra-orçamentário

\begin{tabular}{|c|c|c|c|c|c|c|c|c|}
\hline \multirow[t]{2}{*}{ A.5 Secretarias } & \multirow[t]{2}{*}{$\begin{array}{l}\text { A.6 } \\
\% 1\end{array}$} & \multirow[t]{2}{*}{$\begin{array}{l}\text { A.7 } \\
\% 2\end{array}$} & A.8 & A.9 & A.10 & A.11=(8+9)-10 & A.12 & A.13=10-11 \\
\hline & & & 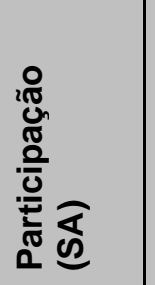 & 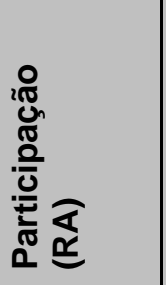 & 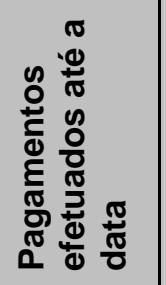 & 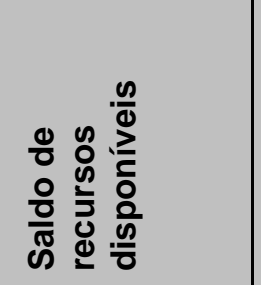 & 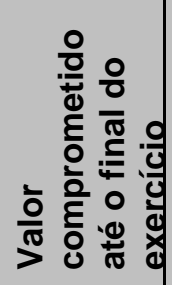 & 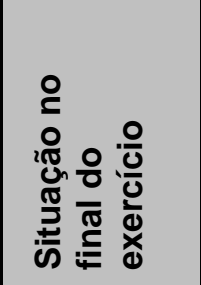 \\
\hline Câmara & $2 \%$ & $3 \%$ & 3.878 & 194.938 & 91.995 & 106.821 & 98.640 & 8.181 \\
\hline Gabinete & $3 \%$ & $5 \%$ & 5.208 & 324.897 & 205.992 & 124.113 & 175.757 & -51.644 \\
\hline Administração & $3 \%$ & $5 \%$ & 5.872 & 324.897 & 166.419 & 164.350 & 176.684 & -12.334 \\
\hline Finanças & $7 \%$ & $10 \%$ & 12.345 & 649.793 & 308.151 & 353.987 & 315.188 & 38.799 \\
\hline Educação & $55 \%$ & $34 \%$ & 104.002 & 2.209 .298 & 1.056 .672 & 1.256 .628 & 1.190 .039 & 66.589 \\
\hline Obras & $12 \%$ & $20 \%$ & 23.062 & 1.299 .587 & 654.441 & 668.208 & 559.297 & 108.911 \\
\hline Saúde & $14 \%$ & $15 \%$ & 26.837 & 974.690 & 528.154 & 473.373 & 582.195 & -108.822 \\
\hline Agricultura & $3 \%$ & $6 \%$ & 6.542 & 389.876 & 180.083 & 216.335 & 130.802 & 85.533 \\
\hline Planejamento & $1 \%$ & $2 \%$ & 1.002 & 129.959 & 58.061 & 72.900 & 31.188 & 41.712 \\
\hline DTAIS & $100 \%$ & $100 \%$ & 188.748 & 6.497 .934 & 3.249 .968 & 3.436 .714 & 3.259 .790 & 176.924 \\
\hline
\end{tabular}

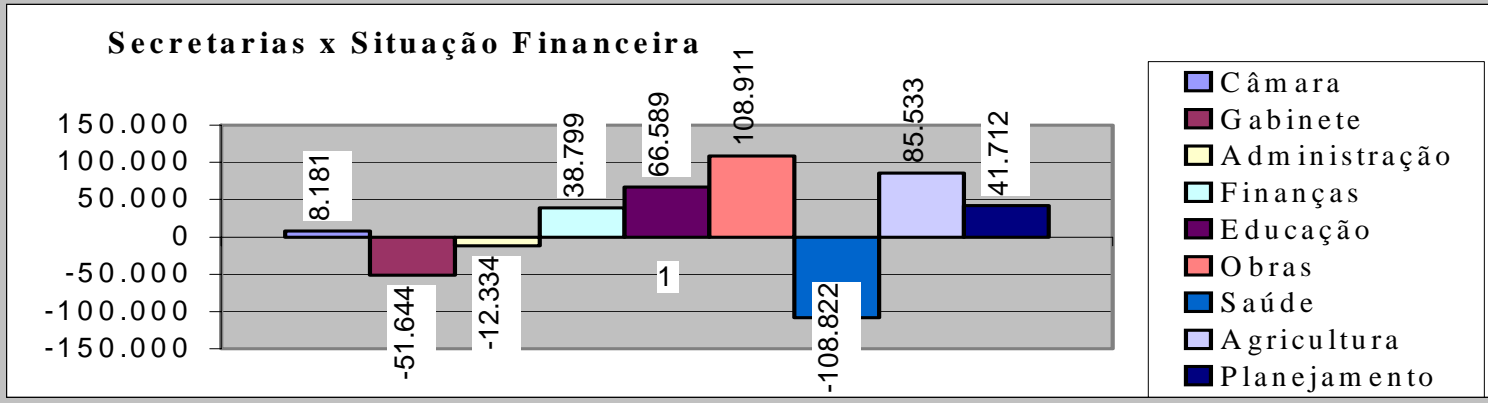

B Previsão geral da situação financeira para 31/12/

\begin{tabular}{|l|r|l|r|}
\hline \multicolumn{2}{|c|}{ RECEITAS } & \multicolumn{2}{c|}{ DESPESAS } \\
\hline B.1 Saldo financeiro na data do relatório & 436.714 & B.4 Previsão de pagamento até 31/12 & 3.259 .790 \\
\hline B.2 Previsão de arrecadação até 31/12 & 3.000 .000 & B.5 Conciliações extra-orçamentárias & 0 \\
\hline B.3 Total dos recursos & 3.436 .714 & B.6 Saldo a utilizar & 176.924 \\
\hline
\end{tabular}

Fonte: Prefeitura Municipal de Restinga Seca (valores hipotéticos) 


\subsection{Participação das secretarias no resultado financeiro (A)}

Em um primeiro momento o relatório evidencia a provável participação de cada secretaria no resultado financeiro do final do exercício podendo ser explicado da seguinte forma:

- Campos A.1, A.2 e A.3 : representam os saldos em caixa e bancos do encerramento do exercício anterior, o valor arrecadado da receita orçamentária até o momento do levantamento do relatório e a projeção da provável arrecadação das receitas orçamentárias para o período restante do ano, evidenciando assim o total de entradas de recursos financeiros orçamentários do exercício.

- Campo A.4: representa a diferença entre o total das entradas de receitas extra-orçamentárias e pagamentos extra-orçamentários até a data do levantamento do relatório, saldo que embora não distribuído entre os órgãos influencia nas disponibilidades. No caso em estudo não houve diferença, porém é bastante comum a sua ocorrência, devendo ser evidenciado com sinal negativo quando os pagamentos desta natureza forem maiores do que os respectivos recebimentos.

- Campo A.5: representa todos os órgãos do Município pelos quais estão divididas as despesas.

- Campos A.6 e A.7: representam os percentuais de participação conforme previsão orçamentária de cada órgão na receita do ano anterior e na receita do ano atual para fins de realizar a distribuição dos recursos.

- Campo A.8: representa a distribuição do saldo anterior evidenciado no campo A.1 pelos órgãos baseando-se no percentual de participação constante no campo A.6.

- Campo A.9: representa a distribuição das receitas evidenciadas nos campos A.2 e A.3 pelos órgãos baseando-se no percentual de participação constante no campo A.7.

- Campo A.10: representa o total dos pagamentos das despesas orçamentárias e restos a pagar de cada secretaria efetuados até a data do levantamento do relatório. 
- Campo A.11: representa a diferença do total dos recursos disponíveis (englobando receita arrecadada e projeção) e do total dos recursos utilizados no pagamento de despesas.

- Campo A.12: representa o total da contas empenhadas e não pagas até a data do levantamento do relatório, bem como as despesas referentes ao ano, que embora não empenhadas possuem caráter continuado ${ }^{5}$ ou que já estão líquidas e certas podendo-se citar despesas com pessoal e encargos, despesas de manutenção tais como água, luz, telefone, assinaturas, contratos, repasses legais etc. Para a obtenção desta informação é de fundamental importância que o Município possua um relatório de controle mensal destas despesas discriminado por secretaria, o qual permitirá que seja feita uma média de gastos.

- Campo A.13: representa a diferença entre o total dos recursos disponíveis e o total dos compromissos já assumidos até o final do exercício por cada órgão.

\subsection{Previsão geral da situação financeira para 31/12 (B)}

Em um segundo momento faz-se uma previsão geral da situação financeira, que representa um resumo do relatório analítico por secretaria, evidenciando:

- Campo B.1: saldo de recursos disponíveis em caixa e bancos constante no balancete do Município até a data do levantamento do relatório, o qual deverá fechar com o somatório dos valores constantes nos campos A.1, A.2 e A.4 diminuído dos valores constantes no campo A.10.

- Campo B.2: total da projeção da receita orçamentária a arrecadar no restante do exercício constante no campo A.3.

- Campo B.3: somatório dos campos B.1 e B.2

- Campo B.4: total de pagamentos a realizar constantes no campo A.12.

- Campo B.5: valor do saldo extra-orçamentário constante no campo A.4 para fins de conciliação do resultado final, evidenciando o saldo a utilizar do campo B.6 com o mesmo valor do somatório do campo A.13, tendo em vista que o município é um simples depositário dos valores extraorçamentários. 
- Campo B.6: resultado global da situação financeira do exercício em 31 de dezembro.

\subsection{Objetivos e Finalidades do relatório}

O relatório pode projetar, em qualquer período do ano, a situação financeira do município no final do exercício, considerando a provável estimativa de arrecadação, as despesas já empenhadas a pagar e os compromissos que mesmo não estando empenhados possuem contratação líquida e certa, podendo-se obter dois resultados evidenciados no campo 13:

a) saldo positivo: significa que o Município ainda poderá contrair novas despesas neste valor sem afetar a situação financeira;

b) saldo negativo: significa que o Município não terá recursos para saldar os compromissos já assumidos, devendo, neste momento, fazer um reestudo de suas despesas, bem como, tomar medidas para o aumento da arrecadação.

O resultado ideal é que todas as secretarias possuam, no mínimo, um saldo positivo que represente a média de despesas variáveis por elas praticadas, o que significa que poderão continuar trabalhando no mesmo nível operacional.

As informações geradas no relatório têm a finalidade de permitir ao administrador saber a qualquer momento:

a) a possibilidade de contrair novos gastos sem comprometer o equilíbrio financeiro exigido pela Lei de Responsabilidade Fiscal;

b) quais as secretarias estão sendo responsáveis pelo endividamento a curto prazo; e

c) o provável resultado financeiro no final do exercício, permitindo-o tomar medidas preventivas no sentido de contenção de despesas ou aumento da arrecadação.

\subsection{0 relatório gerencial e o orçamento}

\footnotetext{
5 “Despesa de caráter continuado é aquela decorrente de lei, medida provisória ou ato administrativo normativo que fixe obrigação legal de sua execução por um período superior a dois exercícios”. (KHAIR, 2000, P. 28)
} 
O déficit ou superávit apurado pelo orçamento representa um dos principais indicadores da situação financeira, porém, considera apenas as receitas e despesas empenhadas no exercício. O relatório gerencial desenvolvido vai além, considerando a influência dos restos a pagar, dos saldos anteriores, das receitas e despesas extra-orçamentárias e das despesas que embora não empenhadas possuem realização líquida e certa. Além disso, refaz as estimativas das receitas considerando, assim, a probabilidade mais correta de arrecadação.

Logo, pode-se dizer que o relatório gerencial desenvolvido vem ampliar as informações do orçamento.

\section{Conclusões}

A Lei de Responsabilidade Fiscal constitui-se num marco na história das finanças publicas do país, tendo por principal objetivo aprimorar a responsabilidade na gestão fiscal dos recursos públicos, dando ênfase ao planejamento, a transparência, ao controle e, principalmente, atribuindo severas penalidades aos administradores que fizerem mau uso dos recursos públicos, sendo na responsabilização, que expressa seu principal diferencial em relação às legislações anteriores.

Neste contexto surge a necessidade de um planejamento que, realmente, norteie as ações governamentais, bem como a existência de informações precisas para a tomada de decisões, assumindo o orçamento e a contabilidade as suas verdadeiras funções, que ultrapassam um simples atendimento a formalidades legais, para servir de base para a tomada de decisões.

A Lei de Responsabilidade Fiscal despertou nos administradores a necessidade de informações mais complexas para a administração das finanças públicas, apresentando-se neste trabalho um relatório gerencial que através da reunião de dados contábeis e orçamentários evidencia a situação financeira a curto prazo, sendo um importante instrumento de controle e estando sua eficácia dependente da existência de controles contábeis confiáveis.

Logo, pode-se dizer que a era da responsabilidade fiscal, onde a sociedade não tolera mais conviver com administradores irresponsáveis e está cada vez mais consciente de que quem paga a conta do mau uso do dinheiro público é o cidadão, traz também a era do desenvolvimento da contabilidade gerencial na administração pública como um instrumento gerador de informações capazes de atender às 
exigências da Lei e dos administradores, que agora, mais do que nunca, deverão controlar suas contas.

\section{REFERÊNCIAS BIBLIOGRÁFICAS}

Angélico, João. Contabilidade Pública: atualizado de acordo com a Constituição de 1988. 7. ed. São Paulo: Atlas, 1989.

Araújo, Luiz Antônio.Novos prefeitos, velhos problemas. Zero Hora. Porto Alegre: 7 jan. 2001, p. 6. 2001, p. 6.

Prefeitos limitam gastos com pessoal. Zero Hora. Porto Alegre: 18 mar.

Baptista, Antonio Sérgio. A lei de responsabilidade fiscal e o encerramento do exercício de 2000-as disponibilidades de caixa e os restos a pagar. Disponível em: <http// www.federativo.gov.br. Acesso em: 2 mai. 2001.

Brasil. Lei complementar n. 101 de 04 de maio de 2000. Estabelece normas de finanças públicas voltadas para a responsabilidade na gestão fiscal e dá outras providências.Brasília, 2000.

Competência desafiada. Zero Hora. Porto Alegre, 18 mar. 2001, p. 16.

Delegação das Prefeituras Municipais. Encontro sobre responsabilidade fiscal. Porto Alegre, 2000.

. Encontro com Prefeitos. Porto Alegre, 2001.

Iglesias, Simone. Lei assusta prefeitos empossados. Correio do Povo: Porto Alegre, 07 jan. 2001, p. 2.

ludícibus, Sérgio de. Contabilidade gerencial. 4 ed. São Paulo: Atlas, 1991.

Khair, Amir Antônio. Gestão fiscal responsável simples municipal: guia de orientação para prefeituras. Brasília: Ministério do Planejamento, Orçamento e Gestão; BNDES, 2001.

. As transgressões à lei de responsabilidade fiscal e correspondentes punições fiscais e penais. Brasília: Ministério do Planejamento, Orçamento e Gestão; BNDES, 2000.

Kohama, Heilio. Contabilidade pública. 6 ed. São Paulo: Atlas, 1998.

Machado Jr., José Teixeira, Reis, Eraldo da Costa. A lei 4320 comentada: com introdução de comentários à lei de responsabilidade fiscal. 30. ed. rev. atual. Rio de Janeiro: IBAM, 2000/2001.

Mesquita, Ronaldo S.de. Novo enfoque do exame das contas públicas. Disponível em: <http//www.federativo.gov.br>. Acesso em: 16 mai. 2001. 
Oliveira, Juarez de. Constituição da república federativa do Brasil. 13 ed. atual. amp. São Paulo: Saraiva, 1996.

Prefeito adota tática do chorinho. Zero Hora. Porto Alegre, 18 mar. 2001, p. 8.

Prefeitura Municipal de Restinga Sêca. Secretaria de Finanças. Orçamentos e demonstrativos contábeis de 1999 e 2000.

Silva, Lino Martins da. Contabilidade governamental. 3 ed. São Paulo: Atlas, 1996.

Tribunal de Contas do Estado do Rio Grande do Sul. Manual de procedimentos para aplicação da lei de responsabilidade fiscal. Porto Alegre, 2000. 